\title{
El descubrimiento del neoliberalismo: El traductor de Salvador Benesdra*
}

Fecha de recepción: 19 de octubre de 2021

Fecha de aprobación: 6 de diciembre de 2021

\section{Resumen}

A pesar de que el neoliberalismo ha sido el sistema económico dominante y la ideología hegemónica en América Latina durante los últimos cuarenta años, son pocos los estudios que abordan su relación con la literatura latinoamericana; de allí el interés de estudiar El traductor de Salvador Benesdra. Para tal fin, el análisis se apoya en los críticos que han historiado las reformas neoliberales (Harvey, Escalante Gonzalbo), en los que han cuestionado sus fundamentos ideológicos (Ahmed, Laval y Dardot) y, también, en los que se han ocupado de la obra de Benesdra (Avaro, Vitagliano). El resultado es una lectura de cómo Benesdra, durante la década de 1990, realiza una representación del nuevo orden neoliberal en diferentes ámbitos sociales (el laboral, el afectivo, el político, el cultural) y una reflexión respecto a la crítica que articula sobre este tema. En última instancia, también se muestran los vasos comunicantes existentes entre el neoliberalismo y la literatura latinoamericana.

Palabras clave: literatura y sociedad, neoliberalismo, novela argentina contemporánea, novela latinoamericana contemporánea, Salvador Benesdra.

Citar: Guzmán Rubio, Federico. "El descubrimiento del neoliberalismo: El traductor de Salvador Benesdra". La Palabra, núm. 41, 2021, e13520. 다 https://doi.org/10.19053/01218530.n41.2021.13520

\section{Federico Guzmán Rubio}

Doctor en Literatura Europea por la Universidad Autónoma de Madrid. Profesor asociado de tiempo completo en el Instituto Tecnológico Autónomo de México.Federico.Guzman@ itam.mx

(D.https:/orcid.org/0000-00032407-7128

* Artículo de investigación. El artículo se inscribe dentro del proyecto de investigación: "Literaturas de la memoria en América Latina: una lectura hacia el futuro", y fue escrito gracias al financiamiento del Sistema Nacional de Investigadores, del Consejo Nacional de Ciencia y Tecnología de México. 


\title{
Salvador Benesdra's view of Neoliberalism in El traductor [The Translator]
}

\begin{abstract}
The study of El traductor [The Translator] focuses the relationship between Latin American neoliberalism and literature. Nevertheless, neoliberalism as the main economic and political hegemonic system in the region since 1940's, it has not been studied in connection with literature. In this paper, the History of neoliberalism reforms are considered where it has been criticized their ideological support. At the same time, it is exposed the patterns presented in Benesdra work related to Latin American neoliberalism. The result is an approach of how the author represented the power of neoliberalism in different scopes like social frameworks, labour sphere, emotional scenarios, and political and cultural contexts. Additionally, it is outlining Brenesda's critical view of neoliberalism.
\end{abstract}

Key words: Salvador Benesdra, Neoliberalism, contemporary Latin American novel, contemporary Argentinian novel, literature and society.

\section{O descobrimento do neoliberalismo: O tradutor de Salvador Benesdira}

\section{Resumo}

Apesar de que o neoliberalismo tem sido o sistema econômico dominante e a ideologia hegemônica na América Latina durante os últimos quarenta anos, são poucos os estudos que abordam a sua relação com a literatura latino-americana; dali o interesse por estudar O tradutor de Salvador Benesdra. Com esse objetivo, a análise apoia-se nos críticos que têm historiado as reformas neoliberais (Harvey, Escalante Gonzalbo), nos que têm questionado seus fundamentos ideológicos (Ahmed, Laval y Dardot) e, também, nos que têm se ocupado da obra de Benesdra (Avaro, Vitagliano). O resultado é uma leitura de como Benesdra, durante a década de 1990, desenvolve a representação de uma nova ordem neoliberal em diferentes âmbitos sociais (laboral, afetivo, político, cultural) e uma reflexão respeito da crítica que articula sobre o tema. Por fim, são apresentados os vasos comunicantes existentes entre o neoliberalismo e a literatura latino-americana.

Palavras-chave: literatura e sociedade, neoliberalismo, romance argentino contemporâneo, romance latino-americano contemporâneo, Salvador Benesdra. 


\section{Introducción}

En la novela El traductor, publicada póstumamente en 1998, el argentino Salvador Benesdra muestra las bases del nuevo mundo que empezaba a consolidarse, basado en las reformas económicas del neoliberalismo y en el cambio social y cultural que estas implicaron. El objetivo de este trabajo es, entonces, analizar hasta qué punto Benesdra intuyó algunos de los principales cambios que acompañarían la neoliberalización de la sociedad, pues El traductor puede leerse ahora, a veintitrés años de su publicación, como la novela latinoamericana que más consciente y críticamente ha reflexionado sobre el neoliberalismo como ideología, mediante la representación sistemática de varias de sus consecuencias concretas en la sociedad. Para tal fin, mediante el análisis textual y apoyándose en algunos de los principales historiadores y críticos del neoliberalismo (David Harvey, Fernando Escalante Gonzalbo, Sara Ahmed, Christian Laval y Pierre Dardot), se proponen varios ejes temáticos de la novela en relación con algunas características definitorias de la deriva neoliberal, con el fin último de reflexionar sobre esta doctrina económica, movimiento ideológico y corriente cultural desde la literatura.

Las diferentes tramas que articulan la novela permiten explorar diversas facetas del fenómeno neoliberal. El traductor se estructura principalmente a través de dos tramas intercaladas: por un lado, están los problemas laborales que surgen en la editorial "progresista" Turba, en la que trabaja Ricardo Zevi, el protagonista de la novela, a raíz de la "reestructuración" llevada a cabo por los dueños; y, por otra parte, está la relación amorosa que Zevi establece con Romina. Si bien ambas tramas nunca se mezclan, claramente lo que sucede en una tiene consecuencias en la otra, de la misma forma en que el neoliberalismo, estrictamente económico, tiene consecuencias en la esfera afectiva de las personas, $\mathrm{y}$, lo que más nos interesa, su lectura en conjunto permite descifrar diferentes vertientes del fenómeno neoliberal, desde las más evidentes, como lo son las reformas en los centros de trabajo, hasta las que en un principio parecían ajenas a él, como su incidencia en las relaciones sentimentales. A estos dos ejes argumentales hay que sumar un trasfondo reflexivo que surge de la traducción que le encargan a Zevi sobre Brockner — un extraño sociólogo alemán de ultraderecha一, y un escenario, las instalaciones de Turba, que en buena medida resume la deriva de la industria cultural latinoamericana en la década de los noventa del siglo xx.

\section{Hacia una literatura del imaginario neoliberal}

A pesar de que las reformas neoliberales en América Latina se iniciaron hace más de cuarenta y cinco años, en 1975, con el manejo de la economía chilena de los "Chicago Boys", bajo el régimen de Pinochet, y que se extendieron en el continente en los primeros años de la década de 1980 — cuando bajo la presidencia de Miguel de la Madrid empezó, por ejemplo, el proceso privatizador en México-, no abundan en la región novelas que se planteen la problemática de enfrentarse a esta ideología dominante en la actualidad. Resulta llamativo tal ausencia, en una literatura, la latinoamericana, que tradicionalmente ha mostrado especial preocupación por reflejar y analizar la realidad social del subcontinente, como lo muestran las docenas de novelas publicadas alrededor del indigenismo, por ejemplo, o las que se cuestionaron o se comprometieron con la lucha guerrillera de los años 1960 y 1970, o incluso, las 
novelas fundacionales del criollismo que indagaron en la estereotipada relación de civilización y barbarie en la que, según ellas, oscilaría fatalmente la historia latinoamericana.

Por supuesto, aunque sí es una de las pocas novelas que lo hace programáticamente, $E l$ traductor no es la única que se enfrenta al neoliberalismo o que responde a los cambios culturales surgidos de este programa económico. Al respecto, podrían citarse, ciñéndonos a la literatura argentina, novelas como Vivir afuera (1998) de Rodolfo Fogwill, o bien, El trabajo de Aníbal Jarcowski (2008) y La intemperie de Gabriela Massuh (2008), que, junto con la novela que nos ocupa, fueron estudiadas por Vitagliano (2018) como una nueva retórica del realismo motivada por la expansión del neoliberalismo en Argentina, bajo la presidencia de Carlos Saúl Menem en la década de 1990.

Por otra parte, si consideráramos a la novela que no cuestiona las consecuencias sociales del neoliberalismo, sino que las asume como una condición dada y se integra a ellas con complacencia - proceso con el que, paradójicamente, quizás se consigue una representación más fidedigna, aunque acrítica—, entonces el corpus se ampliaría notablemente. En esta vertiente, destacarían los dos movimientos más estudiados de los años noventa latinoamericanos, la década en la que el neoliberalismo todavía se presentaba como la promesa que llevaría al subcontinente americano al primer mundo: el McOndo chileno y el Crack mexicano. Sobre el primero, ya Palaversich señaló que parecía posicionarse más cerca, en una típica operación aspiracional del periodo, de la cultura de la clase media urbana estadounidense que de la realidad latinoamericana; sobre el segundo, Eduardo Becerra comenta:

Los "cronotopo 0 " y los escenarios internacionales por los que se mueven los personajes seductoramente cosmopolitas de las ficciones del crack son mucho más que una elección meramente estética o, quizá mejor decir, que constituyen una elección estética perfectamente acoplada a los rumbos políticos y económicos del periodo: una imagen normalizada de lo latinoamericano en cuanto inscrita en los cauces de la cultura global (Becerra 267).

Ante el optimismo algo inocente de la literatura latinoamericana de la década de 1990, resumida en el McOndo chileno y el Crack mexicano, no resulta sorprendente que El traductor no haya gozado de visibilidad, pues su imaginario iba a contrapelo del de la época, aunque con los años demostró ser mucho más sensato.

Desde luego, también podrían considerarse, bajo la óptica de un cambio de paradigma político y social, todas las novelas articuladas alrededor de la memoria, que denuncian la política de exterminio emprendida por las dictaduras latinoamericanas para terminar no solo con las guerrillas de izquierda, sino con cualquier movimiento con conciencia social mínimamente contestatario. Sin embargo, todas estas novelas, al margen de su grado de ficcionalidad o de la posición del enunciador, que tan claramente clasificó Gamerro para el caso de la dictadura argentina, o de su estrategia discursiva, estudiada por Saban, tienen en común que discurren por un mundo definitivamente cancelado, delante del cual se levanta la nada. A la literatura de la memoria latinoamericana, por definición, no le interesa reflexionar sobre el mundo surgido tras el genocidio cometido por las dictaduras cívico-militares, sino que su campo de interés reside en dar cuenta del momento traumático de la represión. De esta for- 
ma, su lectura resulta esencial para entender las operaciones políticas y militares llevadas a cabo, con el fin de posibilitar la implementación de las reformas neoliberales ${ }^{1}$, pero no para reflexionar sobre los efectos de estas últimas.

Por último, en un recuento a todas luces apresurado de la relación entre literatura latinoamericana y neoliberalismo, que excede el objetivo de este trabajo, podría mencionarse a las novelas escritas en clave distópica, tan abundantes en la región en este siglo XXI. En el artículo de Becerra ya citado, el académico afirma que "Estas ficciones distópicas construyen un relato sobre el impacto de ciertas derivas de la globalización en las sociedades latinoamericanas, resultado de programas políticos y económicos del neoliberalismo [...]" (Becerra 273). Es verdad que el imaginario sobre los efectos del neoliberalismo está presente en la mayoría de las distopías latinoamericanas, que hacen hincapié en la catástrofe ecológica derivada del capitalismo extractor, pero es en dos novelas en las que esta intención se vuelve más explícitas: Salón de belleza (1994), de Mario Bellatin, y El año del desierto (2005), de Pedro Mairal. La primera enfatiza, ante el surgimiento de una epidemia, la ausencia de servicios públicos de salud, derivada de la indiferencia de un Estado debilitado, lo que bien puede leerse incluso como profecía de lo que sucedería en varios países de la región durante la pandemia de la COVID-19. La segunda constituye un correlato fantástico de la crisis argentina de 2001, cuando un periodo de ingobernabilidad se ciñó sobre el país, una vez que la fantasía del éxito neoliberal se hubo disipado.

Por su carácter fantástico, la estrategia retórica de las dos novelas mencionadas contrasta con la vertiente realista de El traductor, y mientras las obras de Bellatin y de Mairal exigen ser leídas como una alegoría de las consecuencias de las políticas neoliberales, la de Benesdra permite una lectura más programática, apegada a la estricta realidad $\mathrm{y}$, de hecho, es posible establecer varios paralelismos entre las acciones principales de la trama y algunos puntos cardinales del programa neoliberal.

\section{La muerte del viejo mundo y el nacimiento del nuevo}

Desde su arranque, El traductor se sitúa en una época de transformaciones trascendentales. Ricardo Zevi, narrador y protagonista, deja clara su certeza de que el mundo tal como lo conocía y entendía ya no existe: "Me dije que tal vez era cierto después de todo que las ideologías están muertas" (Benesdra 7). El lector, por su parte, entiende que las páginas que tiene por delante transitarán por un territorio devastado, en el que, ante el vacío que se despliega, todo es posible. Lo que a juzgar por la primera línea podría parecer el inicio de un lamento por las ideas muertas y por la caída de los sistemas con las que se sostenían recíprocamente, de pronto adquiere un nuevo sentido, pues el narrador repara en que ya se está gestando un

Sobre la relación entre neoliberalismo y dictaduras militares en América Latina, vale la pena recordar que fue el propio Milton Friedman, a pedido expreso de Pinochet, quien diseñó el "programa de choque" del neoliberalismo chileno. Friedrich Hayek, el principal ideólogo del neoliberalismo y autor de Los fundamentos de la libertad, por su parte, declaró en su visita a Chile en 1981: "Evidentemente, las dictaduras entrañan riesgos. Pero una dictadura se puede autolimitar y si se autolimita puede ser más liberal en sus políticas que una asamblea democrática que no tenga límites. [La dictadura] puede ser la única esperanza [...], puede ser la mejor solución a pesar de todo" (Escalante Gonzalbo, Senderos que se bifurcan 29). 
nuevo orden, y va más allá al identificar una de sus características definitorias: "la indiferenciación". De nueva cuenta, parece predominar la nostalgia por el pasado, pero Ricardo Zevi, de pronto, de manera inesperada, se posiciona frente al nuevo tiempo con una actitud retadora, casi insolente, que en buena medida justificará sus acciones:

El sol volcaba su fiesta de distinciones sobre todos los objetos de esa esquina, pero yo sentía que por todas partes estaba drenando una noche gris de gatos universalmente pardos, una apoteosis de la indiferenciación que por primera vez no lograba despertarme miedo (Benesdra 7).

Zevi lleva a cabo estas reflexiones en un café, las cuales de pronto se ven interrumpidas por una muchacha adventista, Romina, quien le entrega un folleto con el fin de evangelizarlo. Zevi intenta seducir a la muchacha y le pide que regrese a buscarlo una vez que termine con sus ocupaciones. Para su propia sorpresa, Romina vuelve, y el primer diálogo que intercambian refuerza el tono apocalíptico del texto, al que hay que sumar que ella, de acuerdo con su religión, en verdad está esperando la llegada del apocalipsis:

—Llegaste antes del fin del mundo [...].

- No, lo que pasa es que la evaluación terminó en seguida — dijo finalmente con rostro serio y luego agregó sonriente- ¿ ¿O tuviste que esperar mucho?

Imposible saber a qué se refería con ese "no" inicial, a no ser que sirviera para proteger su orgullo de mujer por haber llegado antes de lo previsible a una cita (Benesdra 19).

A lo largo de la novela, reiteradamente se refuerza la noción de que el mundo anterior ha muerto, lo que despoja a Zevi de cualquier seguridad; él mismo es consciente de este repentino proceso, como cuando comenta que "se me cae la estantería ideológica" (Benesdra 12) o cuando constata que: "En mis huesos se había arraigado la convicción de que toda verdad había muerto en el mundo real y concreto que me había tocado vivir" (Benesdra 280).

Pronto, Zevi mismo notará que los cambios que están transformando al mundo no son solo externos ni suceden en otros continentes. No es casual que la mayor parte de la novela transcurra entre la caída del Muro de Berlín en 1989 y la disolución de la Unión Soviética en 1991, el periodo enmarcado entre los dos acontecimientos más espectaculares que confirmaron el cambio de época. Pero a pesar de que estos sucesos tienen lugar muy lejos de la Argentina, donde se sitúa la novela, en realidad tienen que ver ya no solo con la realidad política y social del país, sino con la vida de Zevi, quien siempre ha tenido clara esta relación directa entre historia y vida:

Pero el grado en que cambia nuestra visión de un lugar, de todos los lugares, es ya impresionante cuando la noticia no se refiere a lo que pasa en otra parte del mundo, y ni siquiera en nuestro propio país, sino a nosotros mismos (Benesdra 151).

Los cambios históricos que se sucedían en Europa coinciden también, como ya se ha mencionado, con dos novedades en la vida de Zevi. Por una parte, está el encuentro con 
Romina, con quien entabla una relación amorosa, y, por la otra, están los cambios experimentados en su lugar de trabajo, la editorial progresista Turba. En esta, los Gaitanes (los dueños, Gaitán padre y Gaitán hijo) empiezan a adoptar medidas acordes con los nuevos tiempos, en concreto, despidos injustificados en aras de "la modernización" de la empresa. La reacción de los empleados es ambigua, y oscila entre periodos de indiferencia y abnegación ante las nuevas reglas del juego con periodos de efervescencia política y rebelión ante los patrones. Así, los cambios históricos encuentran su correlato en la vida sentimental y laboral de Zevi, a quien, siempre fiel a su implacable autoconciencia, no se le escapa el paralelismo: "Mi propia ideología estaba en suspenso desde hacía bastante tiempo, había empezado a estarlo aun más desde que había conocido a Romina, y el entusiasmo sindical en Turba se había esfumado tan rápido como había aparecido" (Benesdra 113).

Romina y Turba le irán mostrando a Zevi las flamantes bases sociales del nuevo mundo, al que él se tiene que ir adaptando sobre la marcha. Ella, por ejemplo, en las pocas discusiones ideológicas que sostienen — pronto se establecerá la relación de dominio machista—, le hace ver que las explicaciones totalizadoras con las que entendía el mundo - en el caso de Zevi, un humanismo de izquierda - se terminaron, y que ahora cualquier verdad es igual de válida, siempre y cuando encuentre quién la defienda. Tal es el caso, para no ir más lejos, de la teoría de la evolución, que a pesar de ser una verdad científica demostrada encuentra un espacio de relativización desde la óptica de Romina, influida por la visión del mundo de algunas sectas protestantes, como la de los adventistas:

- ¡Lo que pasa es que vos no respetás nada de lo que hago o pienso yo! Te creés que sos el único que tiene la verdad, y repetís como un lorito lo que te dijeron en la universidad a la que fuiste vos. Pero no es la única universidad que existe. Hay otras formas de pensar y tenés que saberlas respetar. Ya todo el mundo cuestiona la evolución (Benesdra 147).

A las vivencias de Zevi, hay que agregar el misterioso texto que se encuentra traduciendo, de un tal Brockner, un oscuro autor alemán de ultraderecha. El texto resulta para Zevi igualmente irritante e iluminador, pues parece, desde la desmesura, las premisas y los postulados ideológicos más repugnantes, describir con bastante exactitud el nuevo campo social en el que de pronto se encontró situado. Por ejemplo, Zevi rápidamente se da cuenta, quizás gracias a su conciencia de clase remanente de su periodo marxista, del papel que le tocará representar en el nuevo orden, al margen de los vaivenes políticos de Argentina, que no despiertan en Zevi el menor interés: "En cambio Brockner alababa la democracia porque era para él el sistema más seguro para garantizar el predominio de los superiores y la subordinación convencida de los inferiores" (Benesdra 15). En este mismo sentido, repara Avaro (162), "sus argumentos, aunque desatinados e inaceptables, terminan resultando posibles, es decir, describen $y$, sobre todo, anuncian, a la manera de un vaticinio trastornado pero esencialmente realista, una situación global certera".

De la misma forma que Zevi atestigua con inquietud la destrucción del viejo mundo, pronto surgen propagandistas que ven en la caída del bloque socialista la posibilidad de construir un nuevo orden más dinámico, encima definitivo, en el que la libertad se convierte en el valor supremo por el que se justifica cualquier nueva medida, sea de la índole que sea. 
Según su visión, el predominio de las democracias liberales habría sido la máxima conquista de la humanidad, que estaban destinadas a prevalecer, tanto por sus virtudes insuperables como por la falta de cualquier otra opción política viable. Zevi rápidamente descarta este optimismo, y, en contraste, ve en los últimos acontecimientos históricos la antesala de un tiempo oscuro por venir:

Pero el mundo que vio la revolución rusa de 1917, la alemana de 1918, las huelgas armadas británicas de 1926 y la sindicalización izquierdista de los obreros norteamericanos de los años treinta también mostraba más signos de progreso libertario que de regresión, y sin embargo era sólo la antesala de triunfos fascistas que exigirían a la humanidad la mayor de las guerras habidas para aniquilarlos (Benesdra 251).

El paralelismo entre el acontecimiento histórico y la vida privada llega a su clímax cuando Zevi se entera de la disolución de la Unión Soviética. La desaparición definitiva del eje socialista coincide con una reunión con sus patrones, en la que se le degrada de su puesto, y con una ruptura con Carla, una mujer con la que mantuvo una breve relación durante uno de sus alejamientos de Romina. Al tiempo que todo esto sucede, Zevi continúa con la lectura de Brockner, en la que descifra el nuevo capitalismo que de pronto se acaba de convertir en el modelo hegemónico de todo el mundo:

Pero sobre todo, hay que imaginarme a mí, leyendo esa revisión los días que siguieron a la reunión con Gaitanes, habiendo perdido casi seguro a Carla y sin duda alguna el cargo de lector y sin saber si no me vendría pronto en mi trabajo algo aún peor, con mi pequeño mundo y mi moral sacudidos hasta los cimientos por todo lo que había vivido en Turba y por lo que estaba ocurriendo mucho más lejos, en la URSS, que parecía a punto de disolverse, mientras el comando de áreas espantosamente amplias de su sociedad civil parecía caer en manos de una mafia reconvertida del stalinismo al robo y la trata de blancas (Benesdra 259-260).

A partir de este momento, los acontecimientos de la novela se precipitarán: la relación entre Zevi y Romina se adaptará a los nuevos postulados sociales y la transformación en Turba será más evidente.

\section{El amor y la educación como mercados emergentes}

La figura de Romina sirve para crear un contrapunto con la de Zevi: él es un judío ateo de origen sefardí, blanco, típico habitante del Buenos Aires más culto y progresista, que se dedica a una labor intelectual como lo es la traducción, mientras que ella es salteña, de origen indígena, adventista y aspira a trabajos administrativos básicos. Sin embargo, a lo largo de la novela, ambos transitan por un proceso en que su respectiva identidad se desdibuja para adaptarse a las exigencias del nuevo orden. Que su relación se contextualizará en este queda claro desde el momento en que se conocen, cuando Zevi, tras definir los rasgos identitarios de Romina, concluye: "No podía tener una cotización demasiado alta en el mercado del apareamiento. ¿Y qué cotización tendría yo?” (Benesdra 14).

Aunque esta afirmación de Zevi pueda leerse en clave irónica o cínica, en realidad exige una interpretación literal, a la luz de los postulados del premio Nobel de economía Gary 
Becker, ya que él es uno de los principales responsables de expandir la teoría económica del neoliberalismo a todos los órdenes sociales, y quien dedicó su obra para demostrar que el comportamiento humano y los lazos sociales y afectivos que se establecen a lo largo de la vida responden a una lógica económica. De esta forma, según el economista estadounidense, las personas tienen hijos en un análisis objetivo de costos-beneficios, en el que calculan el costo de criarlos en función del beneficio que obtendrán en un largo plazo, cuando tengan quien los cuide durante la vejez. Siguiendo esta misma lógica, que Becker demuestra mediante modelos matemáticos para imprimir a sus hipótesis validez científica, las personas se casan solo si consideran que obtendrán una ganancia económica cuantificable, por lo que eligen pareja con el único criterio de la utilidad. El matrimonio, y en último término el amor, de esta forma, son un mercado económico como cualquier otro, con algunas peculiaridades, pero que en esencia comparte el mismo mecanismo y los mismos fines que el mercado del acero, el financiero o el de la industria automotriz.

Por su moral protestante, Romina es en principio más proclive a adoptar la nueva noción sobre el ser humano impuesta por el neoliberalismo. Cuando empieza a estudiar administración de empresas, por ejemplo, rápidamente incorpora el discurso meritocrático ${ }^{2}$, una de las estrategias retóricas más eficaces del neoliberalismo, dado su aparente costado incluyente y justo. Zevi al principio le reprocha que haya elegido una carrera meramente utilitaria, pues él considera, en línea con una visión humanística de la educación superior, que la universidad debe formar ciudadanos de una manera integral, y no simplemente prepararlos para ejercer un oficio de acuerdo con las exigencias del sector privado. Pero Romina le hace ver, en el nuevo mundo y según la nueva concepción de la educación, que la única manera en que la universidad beneficie a la sociedad es beneficiando a las empresas, $y$, por lo tanto, su carrera en el fondo busca el bien común: "Los administradores solo tratan de hacer las empresas más eficientes. Hacen que ganen más dinero, para que todos estén mejor" (Benesdra 162). Romina, por supuesto, sintetiza la transformación de la universidad en términos amigables, casi sociales, y su noción de la educación superior coincide plenamente con la del neoliberalismo, que Escalante Gonzalbo (Historia mínima del neoliberalismo 231) describe de la siguiente manera: "La idea de que la educación superior, y la investigación, produjeran bienes públicos ha sido reemplazada por una lógica empresarial, orientada por la rentabilidad y la ganancia privada".

El propio Zevi, asombrado por los vertiginosos cambios a los que tiene que acoplarse con rapidez, repara en la nueva definición de riqueza - que se enseña sin reparos en la universidad pública-, y que básicamente consiste en una posibilidad de abundancia accesible a cualquiera que la merezca, dentro de un marco de competencia en el que todos los individuos parten con las mismas oportunidades. De pronto, los contextos desaparecieron y la responsabilidad de la pobreza, llevando al extremo el discurso de la meritocracia, recayó exclusivamente en los pobres, quienes no supieron aprovechar las oportunidades existentes en la sociedad para hacer dinero:

Para una recapitulación de la construcción de la retórica meritocrática como uno de los pilares del orden neoliberal, así como de su respectivo desmontaje, se recomienda leer a Michael Sandel, La tiranía del mérito: ¿qué ha sido del bien común? 
A medida que [Romina] avanzaba en la facultad no sólo hablaba cada vez más de las distintas formas de hacerse rico, sino que daba a entender de tiempo en tiempo, y con toda la insoportable discreción de una confesión involuntaria, que quien no era rico carecía de la suficiente inteligencia o incluso de ciertos atributos que en un hombre no deberían faltar. En suma: pelotas (Benesdra 168).

Mientras aprenden los nuevos postulados ideológicos del orden de pronto imperante, surge un escollo en la relación de Romina y Zevi, el cual consiste en que ella no alcanza el orgasmo durante sus encuentros sexuales. Zevi la acusa de frígida, y ella incorpora esta culpa. La pareja intenta variar su vida sexual y ella acude a consultar a algún especialista (él nunca lo hace), pero el problema persiste. Entonces, él concluye que lo único que les hace falta experimentar es basar su relación afectiva en un machismo aún más agresivo que el que ya estaba presente, y que se hacía patente mediante la aclaración constante de la superioridad intelectual de Zevi. Este se sorprende a sí mismo al constatar la facilidad con la que adopta este nuevo discurso:

No me vas a cagar, puta de mierda, no te me vas a hacer la difícil para después despatarrarte bajo el primero que te sepa tener cortita, no me vas a tomar el pelo, le dije. E inmediatamente me sentí inmensamente ridículo. Estaba usando el lenguaje que siempre había considerado como una invención caprichosa y cobarde de los hombres más mediocres cuando se topan con la libertad de la mujer. Como imitador de imitadores, sentía que tenía incluso más histrionismo que ellos, lo mío era todavía más artificial e impostados, aunque más no fuera porque ésa era la primera vez que usaba ese tipo de frases y nunca en mi vida había pensado que alguna vez lo haría (Benesdra 61).

En un proceso cuya última manifestación es sin duda repentina, pero que si se analiza había ido construyéndose cuidadosamente, Zevi obliga a Romina a prostituirse. Con ello, además de solucionar su crisis sexual, Zevi pretende obtener una nueva fuente de ingresos, ante los problemas por los que él está atravesando en Turba y por la incapacidad de Romina de incorporarse a un mercado laboral formal que expulsa a sujetos como ella. La prostitución de Romina representa la culminación máxima de las iniciativas de emprendimiento al que el neoliberalismo obliga a los trabajadores, tanto como camino a la realización personal como sustituto de un sistema laboral regulado, como lo ha señalado Vitagliano justamente al analizar este episodio de El traductor: "El neoliberalismo no se conforma con la «mutación industrial», introyecta en los cuerpos una rigurosa disciplina que hace de cada uno el empresario y, a la vez, el explotado de sí mismo" (21). Romina abandona la universidad, pero su paso por ella no fue inútil, pues aprendió la enseñanza fundamental en el mundo neoliberal: todo, incluyendo el propio cuerpo, es sujeto de mercantilización.

Finalmente, tras normalizar su nueva actividad profesional, al grado de ejercerla sin que él mantenga una estrecha vigilancia, como lo hacía al principio, Romina alcanza el orgasmo. A partir de ese momento climático, la relación entra al fin en un periodo de estabilidad y alegría, en consonancia, sin duda, con la prueba de que ambos miembros de la pareja cumplieron su adaptación a los dictados sentimentales del neoliberalismo, en los que, siguiendo a Becker, encontraron un criterio de utilidad cuantificable: las ganancias que ella obtiene mediante su nuevo oficio, que bien puede verse como una empresa en común, gracias a que ella ejerce 
como prostituta y él como proxeneta. Aunque después Romina abandone la prostitución y la pareja contraiga matrimonio, el paso que los llevó a formalizar su relación, siguiendo los dictados del orden burgués más clásico, fue precisamente el emprendimiento de una asociación comercial exitosa, pues las ganancias de Romina como prostituta permitieron a la pareja acceder a un nivel de consumo que antes le estaba vetado.

\section{La precarización laboral y el cambio cultural}

Los cambios implementados en Turba responden al proceso paradigmático de neoliberalización de la cultura laboral. Mediante los eufemismos típicos de la operación neoliberal de precarizar el trabajo — “racionalización”, "reestructuración” (Benesdra 283) -, los Gaytanes emprenden una serie de reformas para disminuir el número de empleados de la empresa, con el propósito de venderla en mejores condiciones a un grupo trasnacional de origen español. Esto solo se sabrá al final de la novela, pues al anunciar y poner en marcha dichos cambios, se les presentan a los trabajadores como un proceso de modernización que, además de inevitable, redundará en su beneficio. Esto no ocurre así, y pronto Zevi descubre que las consecuencias de las transformaciones son exactamente las que señala David Harvey (85) en su ya clásica historia: "El resultado general [de las reformas] se traduce en la disminución de los salarios, el aumento de la inseguridad laboral y, en muchas instancias, la pérdida de los beneficios y de las formas de protección laboral previamente existentes". De hecho, en el nuevo mundo, Zevi era ya una excepción, pues como él mismo repara:

Hacía unos seis años que yo me había convertido en un caso laboral excepcional no sólo para Ediciones Turba, sino probablemente para cualquier otra parte. Era el único traductor raso que yo conocía que trabajaba a sueldo dentro de una editorial de libros (Benesdra 26).

Esta situación alguna vez normal y de pronto privilegiada cambiará pronto, pues Zevi dejará de percibir la parte de su salario que recibía “en negro", será degradado de sus funciones y, por último, recibirá ofertas para abandonar la empresa a cambio de una indemnización. La excusa para deshacerse del personal es la llegada de máquinas que requieren de menos operarios para cumplir con la producción establecida. Sin embargo, pronto los trabajadores demuestran que las máquinas no los sustituyen, sino que más bien exigen una reorganización de las funciones de cada uno, pues de la misma forma en que las máquinas automatizan ciertos procesos, también generan nuevas necesidades. En realidad, lo que la empresa busca es disminuir las responsabilidades laborales con sus empleados, quienes de hecho dejarán de serlo, para entablar un nuevo modelo de relación basada en el trabajo esporádico, irregular o informal.

El hecho de que los cambios tengan lugar en una editorial progresista, decididamente de izquierda, dota a toda la operación de un significado más potente. De haberse tratado de cualquier otra industria, la novela de Benesdra habría sido ejemplar en su representación de los cambios de la cultura laboral impuesta por el neoliberalismo, pero el caso de Turba adquiere otro simbolismo. Por una parte, la editorial asume implícitamente que el contenido de su producción es una mera mercancía especializada como cualquier otra, dirigida a un segmento específico de consumidores. Que la empresa produzca libros de izquierda de ninguna manera 
significa que se adhiera con su contenido, como el mismo Zevi recalca al hablar de Gaitanes, el dueño: "Si puede cerrar el kiosco y darle una patada en el culo a todos es que es otro seguidor de la Thatcher" (Benesdra 110). Por otra parte, al aplicar las medidas que combaten sus libros, Turba certifica la muerte de las ideas que publica, que se convierten en un mero producto, inofensivo, sin mayores consecuencias en el mundo real.

Sería de esperar que, politizados como son, los trabajadores hubieran tenido una reacción decidida ante el nuevo panorama que se les presentaba. A pesar de que ante el primer despido se convoca a una asamblea, en esta no se acuerda nada, salvo organizar una fiesta de despedida al trabajador caído. Esta reacción indolente y festiva de sus compañeros hace que Zevi manifieste que, si bien la editorial publicaba libros sobre los conflictos sociales en medio mundo,

donde no se concebía que hubiera sufrimiento social era en la propia Turba. Los dramas posibles incluían decesos, separaciones, enfermedades, mala suerte en la promoción, todo lo que pudiera ser entendido como una desgracia personal, de ésas que se combaten apechugando y peleando en el rincón de cada uno, no juntando voluntades para una huelga (Benesdra 30-31).

Tras innumerables asambleas, y ya asesorados por un sindicato, los trabajadores enfrentan a los patrones, pero su movilización es limitada. Aquellos a los que se busca despedir lo aceptan al llegar a un acuerdo monetario, y quienes siguen contratados se resignan a las nuevas circunstancias ${ }^{3}$.

Finalmente, la editorial es vendida a un consorcio español que, en cuanto toma el control de la situación, despide a más trabajadores, además de cambiar la línea editorial histórica del sello en consonancia con la actividad de la casa matriz. Si bien el episodio de la conversión de una industria progresista en una empresa neoliberal está motivado por la experiencia del propio Benesdra en Página 12 - el diario de línea progresista de cuya redacción formó parte, del que fue representante gremial y del que fue despedido junto con otros ochenta periodistas en 1995 (Tordini)—, también es posible ver en él la transformación de las editoriales históricas de Argentina e incluso de Latinoamérica ${ }^{4}$. Es sabido que los grandes grupos trasnacionales, en especial Planeta y Random House, adquirieron varios sellos latinoamericanos con prestigio cultural (Joaquín Mortiz, Sudamericana, Emecé o Norma), con lo que su línea editorial quedó desdibujada, como indica Sánchez Prado. Este proceso fue acompañado por el apoyo que varias de las revistas culturales más respetadas de la época, como las mexicanas Vuelta y Nexos, brindaron a la conversión neoliberal, lo que asentó el dominio de la ideología neoliberal en la industria editorial (Lemus).

Queda mucho que decir sobre la mirada de Benesdra sobre la organización de la resistencia obrera frente al neoliberalismo y el papel que los sindicatos juegan o jugaron en ella, pero ese objetivo rebasa los objetivos del presente artículo, pues su análisis, dada la riqueza del material, exige la elaboración de un trabajo autónomo.

$4 \quad$ Resulta sugerente recordar el proceso de publicación de la novela: tras ser rechazada por varias editoriales y quedar finalista en el Premio Planeta Argentina, Benesdra se suicida en 1998 sin ver publicada su novela. Esta se editó en 1998 en Ediciones de la Flor, uno de los escasos sellos independientes que lograron sobrevivir en la década de 1990, gracias a la intervención del crítico Elvio Gandolfo, que la había leído como jurado del premio Planeta. En 2012, El traductor se reeditó en Eterna Cadencia, una de las nuevas casas editoras independientes que surgieron en Argentina tras la crisis de 2001. 
De hecho, el año de publicación de El traductor (1998) coincide con el final de la transformación editorial de la Argentina, tal como afirma Vanoli: "Es justamente en los años transcurridos entre 1997 y 1998 que se termina de producir la concentración y extranjerización del mercado en nuestro país" (169). Además, como ha reparado Malena Botto (220), este proceso sólo puede comprenderse desde la "reforma estructural del Estado" llevada a cabo por el presidente Menem y por su ministro de Economía, Domingo Cavallo. Así, el panorama editorial en el que Benesdra intentó insertarse y publicar su novela era ajeno a cualquier propuesta incómoda y con inquietudes artísticas, más si provenían de un autor desconocido. De Diego resume las nuevas expectativas comerciales surgidas de la "concentración" editorial emprendida por los grandes grupos tras adquirir los sellos literarios: "por lo general poco duran los editores originarios y rápidamente se los reemplaza por técnicos financieros, contadores o expertos en marketing que buscan una rentabilidad mayor y más acelerada" (56).

En este contexto, en el que los sellos literarios del pasado fueron adquiridos por grupos trasnacionales y en el que todavía no llegaba el auge de las editoriales independientes tras la crisis de 2001, El traductor no pudo ser publicado sino de manera póstuma en Ediciones de La Flor, gracias a una edición costeada por los amigos del autor. Benesdra convirtió estas circunstancias en material literario, al grado tal que, junto con otras propuestas de la época, Molina la incluye en su corpus de "relatos de mercado" que, al representar la crisis editorial en la obra literaria, "articulan un mismo régimen de superproducción que desestabiliza el mercado literario-editorial" (21). Podría aventurarse, frente a este conjunto de transformaciones, que El traductor todavía no encuentra el lugar que merece en las instituciones literarias debido a su crítica feroz contra las nuevas estructuras editoriales, más cercanas al mundo empresarial que al cultural.

\section{Conclusiones}

Al final de la novela, los acontecimientos se precipitan y ambas tramas confluyen en lo que podría calificarse como un final feliz. En lo que respecta a Turba, Zevi, gracias a su condición de delegado sindical, consigue un acuerdo bastante beneficioso con la empresa española a cambio de su renuncia. Con parte del dinero recibido, compra un taxi y se dedica con entusiasmo a su nuevo oficio. Y en cuanto a la trama amorosa, Romina y Zevi se casan, tienen un hijo y se compran una casa en el barrio de Avellaneda, con los ahorros que ella conservaba de su trabajo como prostituta y con la otra parte del dinero que Zevi recibió de Turba. Así, finalmente, la pareja formaliza su acoplamiento a la sociedad neoliberal. Esto ya no le produce ninguna incomodidad a Zevi:

En el año que llevo trabajando de taximetrero me pregunté mil veces cómo pude aguantar tanto tiempo en Turba, sabiendo que vivía en un país donde el lugar natural de un ingeniero, un arquitecto, un médico, un físico, un biólogo, un matemático o un traductor que no esté dispuesto a emigrar, está detrás del volante de un taxi, un lugar mucho más saludable que esa cruza de estafa y experimento bucanero que habíamos conocido como empresa progresista (Benesdra 635).

Las expectativas del desarrollo profesional, la posibilidad de formar una familia que no se base en un mero intercambio mercantil y el sueño de lograr una mejor sociedad mediante 
políticas de izquierda han quedado definitivamente cancelados. Esto, lejos de frustrar o incomodar a Zevi, lo llena de alegría. La vida de Zevi resultaría irreconocible para el de apenas unos años atrás, de la misma forma en que la sociedad argentina, en específico, y la latinoamericana, en general, también se transformó por completo en menos de una década. Zevi y Romina saben que para conquistar la felicidad transitaron por una novela tortuosa y retorcida, y en honor a esa trayectoria novelesca nombran a su hijo Román. Dicha novela bien puede leerse como la historia de la transformación de la pareja en un sujeto neoliberal, en los términos planteados por Laval y Dardot: "El mercado se concibe, en consecuencia, como un proceso de autoformación del sujeto económico, como un proceso subjetivo auto-educador y auto-disciplinario mediante el cual el sujeto aprende a conducirse. El proceso de mercado construye su propio sujeto. Es autoconstructivo" (140). Naturalmente, la felicidad que la pareja conquistó es una felicidad neoliberal, en consonancia con la definición que de ella hace Ahmed es decir, la que "se valora o afirma, como signo de la actividad y el valor humano, y puede reformularse como un concepto que implica cierta anestética, entendida como una pérdida de la capacidad o la voluntad de dejarse afectar por las cosas" (420-421). De hecho, el antiguo Zevi encaja en una de las categorías analizadas por Ahmed como sujetos infelices en el neoliberalismo, la del "revolucionario iracundo", y cuando renuncia a esta identidad conquista la plenitud neoliberal, que, en buena medida, se basa en una renuncia.

De esta forma, El traductor puede leerse como la transformación de un personaje y de una sociedad para dejar atrás el anticuado sistema mixto de las décadas de 1960 y 1970, y adaptarse al nuevo orden neoliberal. Finalmente, el héroe conquista su meta: la felicidad neoliberal. Por supuesto, la propuesta está revestida de un desencanto irónico que, por otra parte, es uno de los estados anímicos característicos del periodo neoliberal tras su fase de asentamiento. Queda a la sociedad y a la literatura la labor de imaginar salidas al totalitarismo neoliberal y la creación de nuevas formas de convivencia.

\section{Referencias}

Ahmed, Sara. La promesa de la felicidad. Una crítica cultural al imperativo de la alegría. Buenos Aires, Caja Negra, 2018.

Avaro, Nora. "El gran realista. Salvador Benesdra". La enumeración. Narradores, poetas, diaristas y autobiógrafos. Rosario, Nube Negra, 2016, pp. 157-172.

Becerra, Eduardo. "De la abundancia a la escasez: distopías latinoamericanas del siglo xxi". Cuadernos de Literatura, vol. 20, núm. 40 (agosto 2016): 262-275. Web. 11 Oct. 2021. Doi: https://doi.org/10.11144/Javeriana.cl20-40.aedl

Becker, Gary. A Treatise on the Family. Cambridge, Harvard University Press, 1993. 
Benesdra, Salvador. El traductor. Buenos Aires, Ediciones de la Flor, 1998.

De Diego, José Luis. "Un itinerario crítico sobre el mercado editorial de literatura en Argentina". Iberoamericana, vol. 10, núm. 40 (2010): 47-62. Web. 26 Nov. 2021. https:// bit.ly/3y2mYML

Botto, Malena. "Concentración, polarización y después". Editores y políticas editoriales en Argentina (1880-2010). 2 ed. Ed. José Luis de Diego. Buenos Aires, Fondo de Cultura Económica, 2014, pp. 219-270.

Escalante Gonzalbo, Fernando. Historia mínima del neoliberalismo. México, El Colegio de México, 2015.

----. Senderos que se bifurcan. Reflexiones sobre neoliberalismo y democracia. México, Instituto Nacional Electoral, 2017.

Gamerro, Carlos. “Tierra de la memoria”. Página 12. Página 12, 11 de abril de 2010. Web. 7 Oct. 2021. https://www.pagina12.com.ar/diario/suplementos/libros/10-3787-2010-04-11. html

Harvey, David. Breve historia del Neoliberalismo. Trad. Ana Varela Mateos. Madrid, Ediciones Akal, 2020.

Laval, Christian y Pierre Dardot. La nueva razón del mundo. Ensayo sobre la sociedad neoliberal. Barcelona, Gedisa, 2013.

Lemus, Rafael. Breve historia de nuestro neoliberalismo. Poder y cultura en México. México, Editorial Debate, 2021.

Molina, Cristian. "Relatos de mercado en Argentina (1990-2008)". Badebec, vol. 2, núm. 3 (2012): 1-31. Web. 26 Nov. 2021. https://revista.badebec.org/index.php/badebec/ article/view/39

Palaversich, Diana. De Macondo a McOndo: senderos de la posmodernidad latinoamericana. Barcelona, Plaza y Valdés, 2005.

Saban, Karen. "De la memoria cultural a la transculturación de la memoria: un recorrido teórico". Revista Chilena de Literatura, núm. 101 (mayo 2020): 379-404. Web. 15 Oct. 2021. https://revistas.uchile.cl/index.php/RCL/article/view/57325/65324

Sánchez Prado, Ignacio. "Más allá del mercado. Los usos de la literatura latinoamericana en la era neoliberal”. Libro mercado. Literatura y neoliberalismo. Ed. José Ramón Ruisánchez Serra. México, Universidad Iberoamericana, 2015, pp. 15-40. 
Sandel, Michael. La tiranía del mérito: ¿qué ha sido del bien común? Trad. Albino Santos Mosquera. Barcelona, Debate, 2020.

Tordini, Ximena. "Benesdra, el más oculto de los escritores malditos". Anfibia. Anfibia, 2 de enero de 2018. Web. 1 Oct. 2021. https://www.revistaanfibia.com/benesdra-el-mas-oculto-de-los-escritores-malditos/

Vanoli, Hernán. "Pequeñas editoriales y transformaciones en la cultura literaria Argentina". Apuntes de Investigación del CECYP, núm. 15 (2009): 161-185. Web. 26 Nov. 2021. https://dialnet.unirioja.es/servlet/articulo? codigo $=4509265$

Vitagliano, Miguel. "Tres novelas frente al neoliberalismo: El traductor, El trabajo y La intemperie". Tropelías, núm. 3 (2018): 19-35. Web. 9 Oct. 2021. https://doi. org/10.26754/ojs_tropelias/tropelias.201832654 